\title{
Experimentações e práticas investigativas: reflexões sobre 0 ensino de ciências nos anos finais do ensino fundamental
}

\section{Experiments and investigative practices: reflections on teaching science during the elementary school's last years}

\author{
Leandro Carlos Ody \\ Maristela Longo
}

\section{Resumo}

A escrita deste trabalho tem seu embasamento em dados resultantes de estudos bibliográficos no grande tema ensino de ciências, mais especificamente para os anos finais do ensino fundamental, com o intuito de levantar algumas questões centrais a essa temática. As reflexões apresentadas pautam-se em ações metodológicas que colaborem para o processo de aprendizagem na área de ciências da natureza, por meio de estudo não apenas teórico, mas também contextualizado, com experimentações e atividades práticas e investigativas que promovam a participação dos estudantes e a efetiva compreensão desta área do conhecimento. Inicia-se com uma breve descrição sobre ciências, em seguida são apresentadas algumas reflexões sobre ciências da natureza e sua relação com outros saberes para a promoção da alfabetização científica. Por fim, expõe-se que o conhecimento conceitual em ciências adquire sentido para os estudantes quando este estudo se torna processual, ou seja, no momento em que a experimentação e outras práticas pedagógicas de caráter investigativo passam a ser incluídas nas aulas de ciências.

Palavras-chave: Ensino de ciências. Experimentações. Práticas investigativas.

\section{Abstract}

This work's writing is grounded on data collected in bibliographic studies on the big issue of Science, mostly the elementary school's last years, with the aim of ask a few questions about it. The ideas we presented in here follow methodological actions that help the learning process of Natural Science subject, through a study that not only is theoretical, but is contextualized with experimentations and practical investigative activities that promote both the participation of students and the affective comprehension of this subject. We start our discussion with a brief description of Science, following a few reflections on the Natural Sciences and their relation to other knowledge groups in order to promote scientific literacy. Finally, we discuss that conceptual knowledge in Science make sense on students' learning process when this study becomes processual, in other words, on the moment in which experimenting and other investigative pedagogical practices are included in Science classes.

Keywords: Experiments. Investigative practices. Science teaching.

$$
\begin{gathered}
\text { Recebido em 16/10/2017 - Aprovado em 14/02/2018 } \\
\text { http://dx.doi.org/10.5335/rep.v25i2.8172 }
\end{gathered}
$$

Doutor em Educação pela Universidade de Passo Fundo. Professor da Universidade Federal da Fronteira Sul - Campus Erechim, no curso interdisciplinar em Educação do Campo: Ciências da Natureza - Licenciatura e no Programa de Mestrado Profissional em Educação. E-mail: leandro.ody@uffs.edu.br

** Mestre em Educação pela Universidade Federal da Fronteira Sul. Pedagoga da rede municipal de São Valentim, RS. E-mail: maribarao@hotmail.com 


\section{Introdução}

Comumente nos referimos à relevância de ensinar os conteúdos de ciências para a educação básica por meio de atividades e processos investigativos. Argumentamos esse fato citando que um ensino investigativo desperta a motivação e o interesse dos alunos para os conteúdos desta disciplina, uma vez que as atividades propostas oportunizam a compreensão e o relacionamento desta área do conhecimento ao cotidiano dos educandos.

De fato, o objetivo do ensino de ciências para Zanon e Freitas (2007), Praia, Cachapuz e Gil-Pérez (2002) e Villani e Pacca (2007) está na realização de um ensino investigativo pautado na ação pedagógica para a aquisição do conhecimento científico. Para esses autores, o experimento por si só não possibilita a aprendizagem conceitual.

Nessa perspectiva, enquanto educadores, pensamos o ensino de ciências para os anos finais do ensino fundamental organizado em conteúdos didáticos e teóricos, em conjunto com as denominadas aulas práticas, compreendidas como momentos que utilizam atividades de experimentação e de investigação, a partir de estratégias que partem do educando como sujeito principal na aprendizagem significativa.

Para Campos e Nigro (1999), a aprendizagem significativa está baseada na importância do conhecimento que o aluno tem sobre determinado tema. O estabelecimento de relações facilita a compreensão de que os fenômenos das ciências da natureza não são isolados, mas apresentam relações com o conhecimento sistematizado. Para uma aprendizagem significativa, há que se compreender que o aluno "[...] tem algo a dizer; pensa alguma coisa; vê sob uma perspectiva o fato, o fenômeno e qualquer conteúdo passível de aprendizagem" (CAMPOS; NIGRO, 1999, p. 15).

Partilhando desse conhecimento, desenvolvemos este trabalho com base em referenciais teóricos vinculados ao estudo das experimentações e das práticas investigativas no ensino de ciências da natureza. Inicialmente, apresentamos uma sucinta explicação com relação à diferenciação entre a ciência escolar e a ciência dos cientistas. Remetemo-nos, em seguida, à importância desse conhecimento para a formação do cidadão crítico e atuante em sociedade. Ao final, tecemos argumentos que propiciem a compreensão do leitor para uma aprendizagem ativa em ciências, por meio de um trabalho pedagógico que utilize práticas investigativas e experimentais variadas. 


\section{Contextualizando 0 ensino de ciências nos anos finais do ensino fundamental}

De modo geral, as ciências se constituem na produção cultural humana resultante do constante processo de busca pelo conhecimento do mundo que nos cerca. Pode ter vários objetos como foco de seu estudo, e isso é um dos critérios para as várias subdivisões que existem nessa área do conhecimento humano. No caso da área das ciências da natureza, precisamos percebê-la como a tentativa de compreensão do mundo natural e da interação entre ser humano, enquanto parte do mundo natural, com os demais seres que compõem esse contexto. Nessa relação, o ser humano se constitui e também influencia a existência dos demais seres. A ciência é um conhecimento básico indispensável para aprender a viver e conviver, para nos conhecer e conhecer o outro. É fundamental identificar as relações entre conhecimento científico e produção de tecnologia, a qual, atualmente, é um meio para suprir as necessidades humanas. Nesse processo de construção do conhecimento científico, também é importante focarmos no modo como esse conhecimento chega até aqueles que começam a trilhar os caminhos do saber científico. Torna-se essencial, portanto, analisarmos o ensino de ciências enquanto modo de construção do conhecimento científico e enquanto meio para desenvolver no aluno o espírito crítico, promovendo a elaboração de conceitos sobre os riscos e benefícios das práticas científicas e tecnológicas, necessários ao diagnóstico e à formulação de questionamentos a respeito dos reais problemas científicos e tecnológicos presentes (SELBACH, 2010).

Dessa forma, a ciência "[...] não é um objeto natural, um objeto dado, pois não tem uma fundamentação última na Natureza, nos fatos"; ela é "[...] uma produção cultural, um objeto construído e produzido nas e pelas relações sociais" (LOPES, 1999, p. 114). Por sua vez, conforme a mesma autora, a ciência também não é meramente uma produção cultural qualquer, uma vez que possui relação diferenciada com a verdade, justamente por ter a pretensão da verdade.

Para Chassot (2003b), a ciência não tem a preocupação de descrever e muito menos de explicar o mundo sobrenatural ou espiritual. Sua preocupação está justamente no mundo natural, ou seja, no mundo orgânico e inorgânico, que chamamos de natureza. É para a compreensão deste mundo natural que Chassot considera a ciência como "uma linguagem para facilitar nossa leitura do mundo natural" (1993, p. 37), a fim de entender com esta linguagem a nós mesmos e ao ambiente que nos circunda. Essa visão de ciência deve ser estimulada desde os anos em que a disciplina aparece como área de estudo no contexto escolar.

Segundo Lopes (1999), a característica básica da ciência está na forma de ver o mundo e não em uma metodologia. Desse modo, acreditamos que os educadores devem pautar o trabalho pedagógico em ciências da natureza instigando os alunos 
a verem as ciências da natureza concreta no mundo cotidiano em que habitam. Cabe aos educadores, nesse sentido, estimular nos educandos o interesse pelas ciências da natureza, não para a formação de novos cientistas, mas como meio para melhorar a compreensão dos fenômenos que os cercam e que estão presentes em muitas situações do cotidiano desses alunos.

\section{Para Chassot,}

A mudança de paradigma ocorre com o abandono de uma tradição centrada na transmissão de conhecimentos científicos prontos e verdadeiros para alunos considerados tábulas-rasas, onde haveria uma mente vazia a ser preenchida com informações, para adotar-se orientações construtivistas, cuja postura reside na construção e reconstrução ativa do conhecimento por parte dos envolvidos no processo de ensino-aprendizagem das disciplinas científicas [...]. Assim, alunas e alunos [...] não são analfabetos científicos, pois já chegam às aulas com ideias sobre vários fenômenos e conceitos que, muitas vezes, são diferentes dos que lhes serão ensinados (1995, p. 61).

A compreensão do conhecimento científico respalda-se no entendimento de que esta atividade não se restringe unicamente a experimentos planejados em laboratório. Ou seja, vai além, pois os dados laboratoriais passam a estabelecer relações e regularidades com um conjunto de outros dados, os quais descrevem um sistema e interpretam a natureza por meio de modelos. Desse modo, os dados observados, experienciados, planejados e registrados "tornam-se dados científicos quando se inserem numa atividade que procura estabelecer as suas conexões, mostra como se comportam uns em relação aos outros e quais são as regras do seu comportamento" (DELIZOICOV; ANGOTTI, 2000, p. 35).

Lopes (1999), ao discutir ciências, refere-se a Bachelard (1996) para expor que este autor não trata diretamente a "desmistificação da ciência" em sua discussão epistemológica. No entanto, para Lopes (1999), ao combater o viés ideológico da ciência, os sujeitos acabam por refiná-la ao senso comum. Nesse sentido, há o julgamento de que, se a ciência for fácil e acessível, também será destituída do seu "pedestal de conhecimento restrito aos especialistas" (LOPES, 1999, p. 120). Sendo que,

[...] um dos mecanismos de se manter a ciência como um conhecimento obscuro e inacessível é, justamente, transmiti-la como um refinamento do senso comum. Dessa forma, ao fazermos com que nossos alunos tentem compreendê-la fazendo uso de sua razão cotidiana, impedimos que a compreensão ocorra. Quando muito, alcançamos um arremedo de aprendizagem, a mera capacidade de instrumentalizar-se, mas não de (re)construir criticamente o conhecimento. Átomos são vistos como sistemas solares em miniatura, moléculas como bolas de bilhar, substâncias como caixas de surpresas, prontas a liberarem a energia que têm guardada. Ao tentarem fazer do conhecimento científico uma extensão do conhecimento elementar, aparentemente os continuístas da cultura valorizam o senso comum e, na maior parte das vezes, é isso que objetivam. Mas, em verdade, apenas evitam constrangê-lo, questioná-lo e acabam por dificultar a aprendizagem da racionalidade científica, o que só favorece o poder da ciência (LOPES, 1999, p. 121). 
A ciência tem por característica básica uma forma de ver o mundo. Sua primeira característica é a visão da realidade; assim, a ciência é uma representação abstrata, sob a forma de conceitos, apresentada a partir da razão como uma representação, e não como um reflexo do real. Sua segunda característica são os objetos para descrever e explicar, não para agir. Em terceiro, a ciência se preocupa com a validação de critérios. Não é uma validação por experimento, mas a verificação de um fato científico “[...] que por ser científico já é uma construção e depende de uma interpretação ordenada, dentro de uma teoria explícita” (LOPES, 1999, p. 110).

\section{0 ensino de ciências da natureza e a alfabetização científica}

As ciências da natureza se incorporaram na vida social e se converteram em ponto essencial para interpretar e compreender a cultura contemporânea. A despeito disso, o aluno precisa compreender que sua ação resulta em controle, seleção e manutenção da tecnologia, constituindo a ciência parte fundamental da vida social, cultural e política. Numa sociedade dinâmica, a educação científica

[...] deberá procurar el desarrollo de una capacidad crítica y creativa que permita incidir en la modificación de la realidad social. [...] Parece importante que niños y adolescentes tomen conciencia de la riqueza de las implicaciones e impactos que tienem las ciencias en la vida cotidiana. Por outro lado, la enseñanza de las ciencias favorece em niños y jóvenes el desarrollo de sus capacidades de observación, análisis, razonamiento, comunicación y abstracción; permite que piensen y elaboren su pensamiento de manera autónoma. Además, construyendo su cultura científica, esse niño-adolescente desarrolla su personalidad individual y social. El aporte de las Ciencias de la Naturaleza debería facilitar la aproximación de los alumnos a la realidad natural y contribuir a su mejor integración en el medio social (UNESCO, 2016, p. 4-5).

Vistas deste modo, as ciências da natureza auxiliam na construção do conhecimento científico, na produção de significados e na compreensão dos fenômenos, quando interagem e estabelecem relações com outros saberes, permitindo, para isso, a utilização do lúdico e da imaginação dos alunos, que, na maioria das vezes, são considerados incapazes de pensar, criar e compreender o estudo nesta área (DELIZOICOV; ANGOTTI, 2000).

Assim sendo, faz-se importante um ensino de ciências da natureza em seu conjunto, que apresente uma cultura científica e tecnológica que permita ao educando compreender melhor o mundo em que se insere e que seja capaz de tomar decisões fundamentadas na vida cotidiana. Para a aquisição da cultura científica e tecnológica, o sistema educativo precisa oferecer um ensino de ciências adequado e pertinente ao ensino obrigatório (UNESCO, 2015). 
Segundo Bizzo, "deve-se reconhecer também que a ciência é diferente da disciplina escolar Ciências" (2008, p. 14). Para esse autor, a ciência realizada em laboratório de investigação científica requer um conjunto de procedimentos e atitudes diferentes do que acontece em sala de aula. Tal diferenciação ocorre devido ao fato de que no laboratório de investigação espera-se encontrar resultados inéditos, que expliquem fenômenos. Em sala de aula, o objetivo é alcançar os resultados já esperados, que servirão para a compreensão e/ou o conhecimento de determinado conceito ou conteúdo.

Conforme Chassot (2011), o ensino de ciências em sala de aula precisa ser uma oposição ao cientificismo, preponderante nas escolas e universidades. É essencial olhar a ciência, em especial a estudada na educação básica, com características de uma alfabetização científica, que não é própria das diretamente ligadas à Ciência. Conhecer ciência é fundamental para "[...] entender algo do mundo que nos cerca e assim termos facilitadas algumas vivências" (CHASSOT, 2011, p. 65). Estas vivências não são transitórias, mas contínuas e, portanto, recomendáveis para o investimento em uma alfabetização científica.

Para Chassot (2003a, p. 94), a alfabetização científica permite que o aluno elabore a explicação do mundo natural a partir de um conjunto de conhecimentos adquiridos, que descrevam a natureza como uma linguagem que propicie o entendimento ou a leitura dessa linguagem que é a alfabetização científica. $\mathrm{O}$ autor ainda considera a ciência como uma linguagem necessária para o entendimento do mundo natural, enfatiza que a alfabetização científica é "o conjunto de conhecimentos que facilitariam aos homens e mulheres fazer uma leitura do mundo onde vivem" (CHASSOT, 2011, p. 62).

Mas, o que seria a alfabetização científica ou o letramento científico? E por que a necessidade em compreendê-la? Ambas as expressões são vocábulos que se referem ao ensino das ciências no processo de escolarização básica, inicialmente denominado por scientific literacy, não empregado como domínio de um código nem como as práticas de uso da ciência. Trata-se da forma de destacar a relevância da popularização da ciência, imprescindível quanto à leitura e à escrita, por esta razão entende-se que o aprendizado da ciência precisa atingir todos os sujeitos (TEIXEIRA, 2013).

A ciência configura-se como uma linguagem. Nesse sentido, “[...] ser alfabetizado cientificamente é saber ler a linguagem em que está escrita a natureza. É um analfabeto científico aquele incapaz de uma leitura do universo" (CHASSOT, 2003b, p. 91). Essa alfabetização precisa ser considerada em uma educação mais comprometida, enfatizada significativamente no ensino fundamental, recebendo atenção idêntica também no ensino médio (CHASSOT, 2003a). 
A alfabetização científica faz-se necessária a todos os sujeitos, tanto aos que atuarão em atividades intelectuais, quanto aos que já atuam ou atuarão em atividades invariáveis. Compreender este processo de alfabetização é tão importante como a alfabetização na língua materna, não garante o uso em moldes específicos, mas,

É importante esclarecer que nesta perspectiva, ao se falar de preparo para condições de leitura de textos científicos, não se toma como foco a capacidade de decodificar o que está escrito. Antes sim, refere-se à competência de interpretação sobre o conteúdo da informação, que no caso de textos científicos, para além da decodificação do que é dito, envolve a identificação de evidências empíricas ou teorias que fundamentam o que é dito, interpretação sobre aspectos não verbais da linguagem, tais como: gráficos, tabelas, diagramas, expressões matemáticas, reflexão, e a capacidade de distinguir entre o que é descrição de fatos (observações) e o que é interpretação de fatos (TEIXEIRA, 2013, p. 8).

Ensinar ciências, para Killner (2011, p. 65), é criar condição para que de fato a aprendizagem se realize. Para isso, a escola precisa promover a difusão dos conhecimentos que foram sistematizados e acumulados ao longo do tempo, de forma concreta, inter-relacionados com a realidade social, por meio de uma prática institucional. Outrossim, pressupõe a reorganização das atividades pedagógicas pautadas na reinvenção do currículo e do fazer pedagógico. Ao repensar o currículo fundamentalmente, teremos que reinventar a escola, para que, a partir da criança que temos, possamos chegar ao adulto que queremos.

Para que os educandos passem a entender a ciência, é preciso que compreendam o universo. Para isso, há que se fazer correções em ensinamentos explicados de modo distorcido na etapa da escolarização, em que poucas vezes, como educadores, falamos de prováveis modelos. Os modelos que utilizamos em aula "[...] não são a realidade. São aproximações facilitadoras para entendermos a realidade e que nos permitem algumas (limitadas) generalizações. Talvez a marca da incerteza, hoje tão mais presente na ciência, devesse estar mais fortemente presente em nossas aulas" (CHASSOT, 2003b, p. 98). A ideia da incerteza impulsiona a pesquisa, pois mostra que ainda há muito a descobrir. Diferente é a postura da certeza que aponta o conhecimento como dado, acabado, concluído.

Fazer ciência é permitir a explicação do mundo natural a partir da elaboração de um conjunto de conhecimentos que sejam metodicamente adquiridos, portanto, descrever a natureza em uma linguagem dita científica. Para isso, é preciso propiciar o entendimento e a leitura dessa linguagem, que consiste na alfabetização científica, superando, desse modo, o dogmatismo presente no ensino de ciências (CHASSOT, 2003b).

Alfabetizar cientificamente é levar o aluno a ver a ciência não apenas como a "[...] fada benfazeja que nos proporciona conforto no vestir e na habitação", nos 
fornece medicamentos mais eficazes e baratos, ou alimentos mais saborosos e nutritivos, ou nos facilita a comunicação por meio da tecnologia. Ela pode também ter seu lado vilão, tornando-se uma "bruxa malvada", "[...] que programa grãos ou animais que são fontes alimentares da humanidade para se tornarem estéreis a uma segunda reprodução" (CHASSOT, 2003a, p. 99). Essas duas representações da ciência, a da fada e a da bruxa, precisam aparecer e ser questionadas nas aulas de ciências, construindo-se, nestes momentos, o conhecimento para a alfabetização científica.

Conforme orientações expressas nos Parâmetros Curriculares Nacionais (PCNs) (BRASIL, 1997) em ciências naturais, que, não sendo uma lei, servem como um guia ao professor para o processo de ensino, a aprendizagem decorre do envolvimento do estudante para/com a construção do conhecimento. Reafirma o documento que os conhecimentos prévios têm papel fundamental para o processo de aprendizagem, que ocorre em consonância com o que o aluno já sabe.

A observação, a experimentação, a comparação, o estabelecimento de relações entre fatos ou fenômenos e ideias, a leitura e a escrita de textos informativos, a organização de informações por meio de desenhos, tabelas, gráficos, esquemas e textos, a proposição de suposições, o confronto entre suposições e entre elas e os dados obtidos por investigação, a proposição e a solução de problemas, são diferentes procedimentos que possibilitam a aprendizagem (BRASIL, 1997, p. 29).

Segundo Lorenzetti e Delizoicov (2001), muitas vezes, quando se define a alfabetização científica, refere-se ao pressuposto de que ela alfabetizará o educando cientificamente em assuntos que digam respeito apenas à ciência e à tecnologia, reproduzindo somente conceitos científicos, que não contêm significados e sentidos. Porém, quando se reporta-se à alfabetização científica é porque se quer desenvolvê-la no campo pedagógico, sendo necessário compreender que

A definição de alfabetização científica como a capacidade de o indivíduo ler, compreender e expressar opinião sobre assuntos que envolvam a Ciência, parte do pressuposto de que o indivíduo já tenha interagido com a educação formal, dominando, desta forma, o código escrito. Entretanto, complementarmente a esta definição, e num certo sentido a ela se contrapondo, partimos da premissa de que é possível desenvolver uma alfabetização científica [...], mesmo antes de o aluno dominar o código escrito. Por outro lado, esta alfabetização científica poderá auxiliar significativamente o processo de aquisição do código escrito, propiciando condições para que os alunos possam ampliar a sua cultura (LORENZETTI; DELIZOICOV, 2001, p. 3).

A alfabetização científica está ligada plenamente à formação do cidadão, representada em suas atitudes e habilidades postas em prática cotidianamente. Então, o conhecimento e a vivência trazidos pelos educandos devem ser explorados pela "[...] imensa riqueza que o ambiente próximo oferece à criança e mesmo à sua 
capacidade de manipular ou até construir materiais próprios para uma aprendizagem profícua em Ciências" (DELIZOICOV; ANGOTTI, 2000, p. 52).

\section{Experimentação e práticas investigativas no ensino de ciências da natureza}

Existe a hipótese de que o ensino de ciência da natureza seria melhor aprendido pelos alunos se as aulas não fossem somente teóricas, se envolvessem atividades investigativas e produções diversificadas, com o intuito de auxiliar na compreensão do conteúdo estudado. Nesta parte do trabalho, constam a abordagem do tema atividade experimental no ensino de ciência, bem como a relação entre teoria e prática, estabelecendo a interlocução entre o conhecimento científico e o cotidiano dos educandos.

A aprendizagem em ciência da natureza, conforme Driver e outros (1999), precisa integrar as crianças e os adolescentes a um modo diferente de pensar o mundo natural e de explicá-lo, para que se tornem sujeitos socializados nas práticas do conhecimento científico, com seus objetivos específicos pautados nas assertivas do conhecimento e nas formas de interagir e dar suporte a estes fenômenos do mundo natural. Compreendem os autores que aprender ciências envolve processos pessoais e sociais.

Nesse sentido, busca-se que os educandos tenham interesse pelas ciências da natureza e compreendam o processo de transformação social, científica e tecnológica. Tal aprendizagem se caracteriza por forçosas rupturas, que envolvem a mudança conceitual acerca das ideias informais dos alunos para algo exclusivo da comunidade científica. Tornar-se socializado ou alfabetizado cientificamente "[...] nas práticas discursivas da comunidade científica não significa, no entanto, abandonar o raciocínio do senso comum” (DRIVER et al., 1999, p. 36).

Segundo Hodson (1994), não restam dúvidas de que o entusiasmo dos alunos tem se esvaído nas aulas de ciências da natureza em decorrência de uma investigação meramente de "banco de laboratório". Ficam distantes a atração e a oportunidade para colocar em prática métodos de aprendizagem em ciências da natureza, com atos que proporcionem a interação com o professor e com os outros alunos, por meio de um trabalho que melhor se adapte ao gosto e à curiosidade dos educandos.

De acordo com Hodson (1994), a metodologia presente no trabalho prático nas aulas de ciências e a realização de investigações pouco estruturadas levam os educandos a perder o interesse e o entusiasmo. Todavia, o trabalho pedagógico não pode ser tão difícil que o aluno não possa compreender, nem relativamente fácil que não o estimule. Para realizar um experimento adequado, esse deve ter um objetivo claro e funcionar com a devida medida de controle e independência. 
De acordo com Hodson (1994), as atividades experimentais em ciências da natureza pautam-se grandemente em aprendizagens técnicas, básicas e essenciais para futuros cientistas e técnicos, mas pouco, para não dizer nenhuma interação, que leve à compreensão e à argumentação da ciência cotidiana dos alunos. É essencial refletir que as técnicas experimentais pautadas unicamente a um contexto de laboratório não cabem na educação básica, mas são um meio para alcançar um fim no ensino superior, que tem por objetivo formar cientistas e educadores nesta área do ensino.

As atividades experimentais no ensino fundamental têm sido um pouco mais que "seguir uma receita", desse modo os alunos têm apenas uma simples ideia do que estão fazendo, sem compreender o objetivo do experimento, as razões que levam à realização de tal prática, com um pequeno entendimento dos conceitos subjacentes. Para Hodson (1994), seguir este modelo de atividade prática é perder tempo, provavelmente causará confusão e resultará em contra produções.

Compartilhamos da afirmação de que "aprender ciências envolve ser iniciado". Portanto, este conhecimento, numa posição de construção, não é diretamente transmitido, mas construído de modo ativo pelos educandos e compartilhado por diferentes sujeitos e diferentes momentos da pesquisa e do ensino das ciências (DRIVER et al., 1999, p. 32).

Para que cada sujeito possa compreender e intervir na elaboração do conhecimento, a experiência científica precisa ser orientada pelo educador em um contínuo diálogo da interface "teoria e experimentação". Ambas devem ser questionadas e submetidas a um interrogatório com respostas jamais definitivas, visto que a experimentação é um método de múltiplos e diversos caminhos ajustáveis com a própria situação investigativa. Nesse sentido, os “[...] resultados são lidos como elementos (possíveis) de construção de modelos interpretativos do mundo e não cópias (e muito menos fiéis) do real" (PRAIA; CACHAPUZ; GIL-PÉREZ, 2002, p. 257).

De acordo com Praia, Cachapuz e Gil-Pérez, a prática científica deve ser desenvolvida em um processo composto por três fases: a criação, a validação e a incorporação de conhecimentos; elas correspondem “[...] à geração de hipóteses, aos testes a que a hipótese(s) é sujeita e ao processo social de aceitação e registro do conhecimento" (2002, p. 257).

O papel da hipótese consiste na articulação e no diálogo entre as teorias, as observações e as experimentações. Ela será um guia para que a investigação aconteça em busca dos dados neste percurso descontínuo, intervindo posteriormente nas explicações e nos resultados. A hipótese é uma possibilidade de interrogar, problematizar e, muitas vezes, de conduzir a outras hipóteses. É um diálogo nada simples entre hipóteses, teorias e experimentação, persistindo o confronto entre o teórico 
(idealizado) e o prático (o realizado), que se interligam. Desse modo, se a hipótese intervém ativamente nas explicações sugeridas pelos resultados da experiência, então, a teoria tem um papel essencial na avaliação obtida dos resultados (PRAIA; CACHAPUZ; GIL-PÉREZ, 2002).

No entanto, Praia, Cachapuz e Gil-Pérez (2002) têm observado a inadequada realização da experiência científica em sala de aula. Neste espaço de conhecimento, não se realizam análise e reflexão sobre os resultados referentes à teoria e às hipóteses enunciadas, apenas se constata o previsível ou o que já era anteriormente conhecido. Desse modo, a experiência serve apenas para constatar o que já foi determinado, ignorando os contextos sociais, tecnológicos e culturais da construção e da produção científicas. Quando a experimentação científica segue esse viés, simplesmente segue o sentido do fazer, sem saber por que e para quê, desvalorizando a luta por ideias explicativas para os fenômenos naturais.

A hipótese prevista pelos estudantes precisa ser respaldada com a compreensão do procedimento experimental, de modo que compreendam a natureza do problema e a realização do procedimento, o que não lhes é questionado. Para tanto, a perspectiva teórica necessita estar relacionada com o tema em estudo e com a transposição didática do professor, para que os alunos assimilem e compreendam as instruções do experimento, manejando os materiais, obtendo dados e reconhecimento entre os resultados alcançados, ou os que deveriam ter obtido. Isso faz-se necessário para que se possa interpretar os resultados e (des)escrever as informações obtidas pelo experimento realizado. $\mathrm{O}$ trabalho da experimentação precisa estar livre de inferências, ou seja, de sobrecarga de informações, para que os estudantes sejam capazes de perceber claramente as informações que estão recebendo e construindo (HODSON, 1994).

Conforme Hodson (1994), grande parte das práticas realizadas é mal concebida e confusa, requerendo valor educativo real. O primeiro passo está na construção de um currículo que descreva pedagogicamente a prática científica, para que os estudantes possam compreender o propósito do ensino concreto. $\mathrm{O}$ segundo passo consiste em uma atividade de aprendizagem que se adapte aos objetivos, para que a experiência de aprendizagem pensada facilite o desenvolvimento conceitual necessário à compreensão dos aspectos particulares da experimentação, gerando interesse pela ciência, pela sua história e pelas informações a respeito do impacto social de suas reais intenções.

Para que os objetivos se concretizem, é necessário redefinir e reorientar o conceito de trabalho prático, readaptando as atividades aos objetivos desejados. Para tanto, encontramos em Hodson (1994, p. 305) que o ensino da ciência pauta-se em três aspectos: a) A aprendizagem da ciência precisa adquirir e desenvolver conhecimentos teóricos e conceituais; b) A aprendizagem sobre a natureza da ciência deve 
desenvolver um entendimento de natureza e os métodos de ciência, sendo conscientes das interações completas entre ciência e sociedade; e c) A prática da ciência precisa desenvolver os conhecimentos técnicos sobre a investigação científica e a resolução de problemas.

No entanto, o trabalho pedagógico tem demonstrado que os professores em seus planos de estudo não conseguem realizar a distinção entre a prática da ciência e o ensino pela aprendizagem da ciência. Ou seja, ao desenvolver uma atividade prática com o objetivo de produzir o conhecimento, esta se torna uma atividade meramente demonstrativa, com o mínimo de questionamento. Hodson argumenta que:

[...] cualquier método de aprendizaje que exija a los aprendices que sean activos en lugar de pasivos concuerda con la idea de que los estudiantes aprenden mejor a través de la experiencia directa, por lo que podría ser descrito como "trabajo práctico". En este sentido, el trabajo práctico no siempre necesita incluir actividades que se desarrollen en el banco de laboratorio. Existen otras alternativas válidas como las actividades interactivas basadas en el uso del ordenador, el trabajo com materiales de análisis de casos, las entrevistas, los debates y la representación de papeles, escribir tareas de diversos tipos, hacer modelos, carteles y álbumes de recortes, investigar en la biblioteca, hacer fotografías y vídeos (1994, p. 305, grifo nosso).

Para que esta prática pedagógica se efetive, é necessária a utilização de métodos de ensino e aprendizagem mais amplos em relação aos que se empregam com regularidade nas aulas de ciência da natureza. Para isso, é fundamental adaptar as experiências de aprendizagem de modo específico aos objetivos concretos, realizando as distinções fundamentais que existem entre a aprendizagem da ciência, a aprendizagem sobre a natureza da ciência e a prática da ciência (HODSON, 1994).

Para que a aprendizagem da ciência da natureza seja compreendida pelos educandos, é preciso que se tenham em conta os conhecimentos prévios dos sujeitos envolvidos no processo. Conhecimento científico e conceitos empíricos, da chamada leitura de mundo indicada por Freire (2011), estão num processo ativo de construção e reconstrução do seu próprio entendimento à luz de suas experiências (HODSON, 1994).

Para a compreensão teórica e experimental da ciência da natureza, o trabalho pedagógico deve ter primordialmente um enfoque, que proporcione oportunidades aos estudantes de explorar suas capacidades no momento concreto de compreender e propor seus modelos e teorias. Também é necessária, por parte do professor, a oferta de estímulos para o desenvolvimento de conceitos e capacidades, reelaborando ideias e pontos de vista (HODSON, 1994).

De acordo com Hodson (1994), as atividades práticas em ciência da natureza, quando desenvolvidas, têm sido as que envolvem práticas de laboratório como um 
meio de obter informações e dados que mais tarde serão extraídos de conclusões pertinentes. A desvantagem dessa prática está no que o autor denomina de "dados puros", que não têm interferências das ideias e dos conceitos que os estudantes apresentam. Não ocorre, assim, a participação para a reflexão da investigação experimental.

Por vezes, este trabalho prático de laboratório resulta em um "trabalho inútil" do ponto de vista pedagógico. Um estudante que precise compreender a teoria apropriada não saberá como realizar as observações adequadas ao tema em estudo, nem como interpretá-las. Por conseguinte, a atividade prática resultará improdutiva, não havendo a participação do estudante, sendo necessária a resposta do professor. Quando a prática experimental não se efetiva com o trabalho dos educandos, Hodson aponta que a situação pode chegar a ser muito mais complexa e bastante prejudicial. A despeito disso, os estudantes acabam percebendo "El laboratorio como un lugar donde están activos (en el sentido de "estar haciendo algo"), muchos son incapaces de establecer la conexión entre lo que están haciendo y lo que están aprendiendo (tanto en términos de conocimientos conceptuales como de conocimientos relativos al procedimiento)" (1994, p. 306).

Para que isso não ocorra na prática pedagógica, é fundamental que os educadores adotem uma postura diferente sobre como ensinar e aprender ciências. Esta postura precisa estar embasada em explorar, desenvolver e modificar os conceitos e ideias dos educandos, ao invés de tentar substituí-los. Os estudantes precisam ser estimulados a explorar suas opiniões e capacidade de explicação, animando-os ao mesmo tempo para a produção de novas e necessárias explicações ao que é estudado. Assim, a atividade experimental se torna importante quando se estimula

[...] el desarrollo y la intensificación conceptuales animando a los estudiantes a que exploren, elaboren y supervisen sus ideas existentes comparando las con las aportadas por la experiencia - la experiência "real” y la experiência artificial del experimento científico -, entonces podemos afirmar que el trabajo de laboratorio y las investigaciones en el terreno tienen un importante papel que desempeñar, pero sólo cuando tales actividades tengan una base teórica y sean bien entendidas por el estudiante (HODSON, 1994, p. 307).

Ao compreender que a educação em ciência da natureza deve permear-se "[...] em torno de descriptografar as chaves do mundo físico" (HODSON, 1994, p. 308, tradução nossa) para entender o conhecimento conceitual e processual, então, o primeiro passo deve ser enfocado na familiarização do ensino de ciências com o mundo. Desse modo, será possível que os educandos realizem suas próprias investigações, contribuindo para a compreensão do que é a ciência da natureza.

A prática científica é muito mais do que ter conhecimento da natureza, da observação e da experimentação, inclui a compreensão, a valorização e o relato 
de como a investigação científica acontece. Para ter essa compreensão, é preciso desenvolver uma aprendizagem ativa, por meio de estudos de casos históricos, simulações, reconstruções, discussões orientadas e a realização de atividades com meios tecnológicos e experimentos que envolvam a reflexão (HODSON, 1994).

Tendo uma prática pedagógica elencada nesta perspectiva, os alunos poderão reconhecer a falibilidade e a dependência teórica da observação e da experimentação, entendendo como o conhecimento é produzido cientificamente, inteirando-se de influências socioeconômicas, culturais, políticas, éticas e morais, distinguindo teorias realistas que visam a explicar e instrumentalizar modelos que atuam com medidas de controle (HODSON, 1994, p. 307-308).

$\mathrm{O}$ conjunto de atividades práticas em ciência da natureza permite que os estudantes interajam e compreendam os aspectos da ciência de modo criativo, facilitando a compreensão da natureza e da prática científica; no entanto, há que se ter o devido zelo nas atividades educacionais em que

[...] la mayoría de las lecciones que se imparten en el laboratorio, a los estudiantes no se les ofrece la posibilidad de participar en la elaboración de hipótesis ni en el diseño experimental, debido a que los profesores son reacios a dedicar el tiempo necesario; no quieren hacerse cargo del coste que se derivaría o no quieren correr el riesgo de que los estudiantes adopten estrategias experimentales inadecuadas, ineficaces o potencialmente peligrosas (HODSON, 1994, p. 308).

Para que as atividades de experimentação nas aulas de ciências levem ao questionamento e à elaboração do conhecimento, é essencial que os alunos sejam ensinados a investigar profundamente e refletir sobre o tema estudado. A experimentação não pode simplesmente ser projetada pelo professor antes da aula, para que os alunos a realizem somente seguindo as instruções. Os experimentos realizados em sala de aula, ou na sala de ciências, devem permitir que diferentes grupos de alunos realizem os procedimentos. Desse modo, é possível observar os procedimentos nos grupos, em que alguns têm melhor desempenho, outros, um pouco menos, e alguns não conseguem realizá-los totalmente (HODSON, 1994).

Para Hodson (1994), esta é a ciência real, pois inclui três objetivos de aprendizagem, os alunos: a) aprendem muito mais sobre os fenômenos investigados e os conceitos que podem ser aplicados para explicá-los, porque têm mais tempo para compreender os conceitos; b) adquirem algumas técnicas para elaborar estratégias criativas e de planejamento; e c) compreendem que a ciência é baseada no pensamento, na suposição, constatando que em alguns experimentos obtém-se o resultado esperado e, em outros, não. Ao colocar essas atividades em prática, o mesmo autor compreende que será possível desmistificar a ciência e torná-la acessível às pessoas (HODSON, 1994, p. 308). 
Para que a ciência possa ter sentido aos estudantes, a experimentação e as demais práticas pedagógicas realizadas em aula precisam pautar-se em quatro elementos essenciais: primeiramente, a fase de planejamento e de exposição das concepções, durante a qual realizam-se perguntas, formulam-se hipóteses, procedimentos e técnicas experimentais; em seguida, os experimentos ou as práticas são implementados, e os dados, coletados; na sequência, realiza-se a fase de reflexão, em que são examinados e interpretados os dados experimentais obtidos, com base em diferentes perspectivas teóricas; por fim, ocorre a fase do registro e da preparação de um relatório, em que constam os procedimentos, os resultados alcançados e as muitas descobertas, com interpretações e conclusões para uso pessoal e para a socialização coletiva (HODSON, 1994).

É preciso entender e conhecer a ciência como uma "atividade fluida e holística", não como um segmento dotado de uma série de regras que requerem comportamentos específicos em etapas específicas. A ciência da natureza é uma atividade orgânica, dinâmica e interativa em constante diálogo entre pensamento e ação (HODSON, 1994, p. 308-309).

Segundo Hodson (1994), não se pode aprender a praticar ciência como se fôssemos aprender uma receita ou uma série de processos que podem ser postos em prática em todas as situações. Aprende-se ciência praticando-a. Praticar ciência é uma atividade reflexiva que envolve conhecimento e habilidade para determinar a direção da investigação, para intervir na reflexão e na ampliação do conhecimento.

Ao desenvolver a prática da ciência nos passos descritos por Hodson, é fundamental promover questionamentos e buscar de respostas. Quando os estudantes aprendem a identificar e investigar os problemas importantes, aprendem também a formular perguntas e propor soluções adequadas, entendendo que muitas respostas corretas são provisórias e necessitam ser melhoradas em uma próxima investigação. Cabe destacar, nas palavras de Hodson, que "la investigación científica no siempre es experimental" (1994, p. 309, grifo do autor).

\section{Considerações finais}

Este trabalho, em seu apanhado geral, buscou fornecer conhecimentos conceituais para a prática pedagógica do ensino de ciência da natureza para os anos finais do ensino fundamental. Entendemos que o ensino de ciência nesta etapa da educação precisa estar amparado em múltiplas estratégias para promover a compreensão da aprendizagem dos sujeitos envolvidos.

As múltiplas estratégias de ensino definem-se por um trabalho que vai além de conhecer o conteúdo teórico da ciência. Elas embasam uma aprendizagem ativa 
que leva à prática científica não apenas com atividades experimentais em laboratório, mas também com a elaboração de propostas lacônicas, por meio de simulações, discussões orientadas, observações, relatos e reflexões que promovam a ampla participação dos estudantes a partir das e com as disponibilidades do espaço escolar.

Ao finalizarmos este estudo, reportamo-nos a citação já exposta anteriormente, "aprender ciência envolve ser iniciado". É essencial compreender, no trabalho didático, que toda orientação pedagógica que busca a aprendizagem dos alunos requer uma iniciação do professor, neste caso em específico, nas ciências da natureza: uma iniciação nas diversas práticas que promovam a reflexão e a atuação investigativa pautadas na ampliação do conhecimento.

\section{Referências}

BACHELARD, Gaston. A formação do espírito científico. São Paulo: Contraponto, 1996.

BIZZO, Nelio. Ciências: fácil ou difícil? 2. ed. São Paulo: Ática, 2008.

BRASIL. Secretaria de Educação Fundamental. Parâmetros Curriculares Nacionais: Ciências Naturais. Brasília: MEC/SEF, 1997. Disponível em: <http://portal.mec.gov.br/seb/arquivos/pdf/ livro04.pdf >. Acesso em: 07 jul. 2016.

CAMPOS, Maria Cristina da Cunha; NIGRO, Rogério Gonçalves. Didática de ciências: o ensino-aprendizagem como investigação. São Paulo: FTD, 1999.

CHASSOT, Áttico Inácio. Alfabetização científica: uma possibilidade para a inclusão social. Revista Brasileira de Educação, Rio de Janeiro, n. 22, p. 89-100, jan./abr. 2003a. Disponível em: <http://www.scielo.br/pdf/rbedu/n22/n22a09.pdf>. Acesso em: 17 jul. 2016.

Alfabetização científica: questões e desafios para a educação. 5. ed. Ijuí: Ed. Unijuí, 2011. Alfabetização científica: questões e desafios para a educação. 3. ed. Ijuí: Ed. Unijuí, 2003b. Catalisando transformações na educação. Ijuí: Ed. Unijuí, 1993.

Para que $(m)$ é útil o ensino? Alternativas para um ensino (de Química) mais crítico. Canoas: Ed. da Ulbra, 1995.

DELIZOICOV, Demétrio; ANGOTTI, José André Peres. Metodologia do ensino de ciências. São Paulo: Cortez, 2000.

DRIVER, Rosalind et al. Construindo conhecimento científico na sala de aula. Química Nova na Escola, São Paulo, n. 9, p. 31-40, maio 1999. Disponível em: <http://qnesc.sbq.org.br/online/ qnesc09/aluno.pdf>. Acesso em: 23 jul. 2016.

FREIRE, Paulo. Pedagogia da autonomia: saberes necessários à prática educativa. São Paulo: Paz e Terra, 2011. 
HODSON, D. Hacia um enfoque más crítico del trabajo de laboratório. Ensenãnza de las ciencias. Revista de Investigación y Experiencias Didácticas, Espanha, v. 12, n. 3, p. 299-313, 1994. Disponível em: <https://dialnet.unirioja.es/servlet/revista?codigo=497>. Acesso em: 02 jul. 2016.

KILLNER, Gustavo Isaac. Em busca das propriedades da ciência. Educação, São Paulo, v. 1, p. $62-75,2011$.

LOPES, Alice Ribeiro Casimiro. Conhecimento escolar: ciência e cotidiano. Rio de Janeiro: Eduerj, 1999.

LORENZETTI, Leonir; DELIZOICOV, Demétrio. Alfabetização científica no contexto das séries iniciais. Ensaio - Pesquisa em Educação em Ciências, Belo Horizonte, v. 3, n. 1, p. 1-17, jun. 2001. Disponível em: <www.portal.fae.ufmg.br/seer/index.php/ensaio/article/download/35/66>. Acesso em: 02 jul. 2016.

PRAIA, João; CACHAPUZ, António; GIL-PÉREZ, Daniel. Hipótese e a experiência científica em educação em ciência: contributos para uma reorientação epistemológica. Ciência \& Educação, Bauru, v. 8, n. 2, p. 253-262. 2002. Disponível em: <http://www.scielo.br/scielo.php?script=sci_ar ttext\&pid=S1516-73132002000200009>. Acesso em: 23 jul. 2016.

SELBACH, Simone. Ciências e didática. Petrópolis, RJ: Vozes, 2010.

TEIXEIRA, Francimar Martins. Alfabetização científica: questões para reflexão. Ciência \& Educação, Bauru, v. 19, n. 4, p. 795-809, 2013. Disponível em: <http://www.scielo.br/pdf/ciedu/v19n4/ v19n4a02.pdf >. Acesso em: 17 jul. 2016.

UNESCO. Situación Educativa de América Latina y el Caribe: hacia una educación para todos. 2015. Disponível em: <http://www.unesco.org/new/fileadmin/MULTIMEDIA/FIELD/Santiago/ pdf/situacion-educativa-mexico-2013.pdf>. Acesso em: 10 jul. 2016.

UNESCO. Importancia de la enseñanza de las ciencias em la sociedad actual. Disponível em: <http://www.unesco.org/education/educprog/ste/pdf_files/curriculo/cap1.pdf>. Acesso em: 10 jul. 2016.

VILLANI, Alberto; PACCA, Jesuina Lopes de Almeida. Construtivismo, conhecimento científico e habilidade didática no ensino de ciências. Revista da Faculdade de Educação, São Paulo, v. 23, n. 1, p. 196-214, jan./dez. 1997. Disponível em: <http://www.scielo.br/scielo.php?script=sci_ arttext\&pid=S0102-25551997000100011>. Acesso em: 27 maio 2017.

ZANON, Dulcimeire Volante; FREITAS, Denise. A aula de ciências nas séries iniciais do ensino fundamental: ações que favorecem a sua aprendizagem. Ciências \& Cognição, Rio de Janeiro, v. 10, p. 93-103, 2007. Disponível em: <http://www.cienciasecognicao.org.>. Acesso em: 31 maio 2017. 